\title{
EARTHQUAKE DESIGN OF RECTANGULAR UNDERGROUND STRUCTURES
}

\author{
J.H. Wood ${ }^{1}$
}

\begin{abstract}
Severe damage to six out of a total of 21 subway stations in the Kobe area during the 1995 Hyogoken-nanbu earthquake indicated a need for more attention to be given to the earthquake design of rectangular underground structures. This paper presents work undertaken to extend the present knowledge of the dynamic interaction of boxsection structures with the surrounding soil, and a design method for predicting the earthquake loads on underground structures such as basement walls, tanks, subways, utility boxes, highway underpasses, and culverts.
\end{abstract}

\section{INTRODUCTION}

Seismic design methods for underground structures are not adequately covered in New Zealand design codes and guidelines. For example, the current Transit New Zealand Bridge Manual identifies the problem of the seismic design of underground structures for culverts and subways with moderate depths of cover, but suggests using an outof-date analysis procedure known as the "stresses at infinity method".

Many small underground structures exist in urban areas in New Zealand. For example there are about 13 underground subways, box culverts and highway underpasses in the Lower Hutt City area located in sediments close to the Wellington Fault. None of these have been specifically designed for earthquake effects. Large underground car-parking buildings and buildings with significant underground basement structures have been constructed in major New Zealand cities. Earthquake loads have usually been considered in their design, but the analyses have been based on simplified theory developed for retaining walls with the wall top at the ground surface and the foundation assumed to be rigid. When the structure is constructed below the surface in deep soil layers, these simplified methods have obvious limitations.

Underground structures are constrained by the surrounding soil or rock and cannot move independently so are not generally subjected to significant dynamic amplification effects. They are affected by the deformation of the surrounding ground and not by the inertia forces acting on the structure. In contrast, above-ground structures often have natural frequencies that are within the range of the predominant frequencies of earthquake ground motions, resulting in resonant effects with the accelerations acting on the structure amplified with respect to the ground surface.

The earthquake response of underground structures is usually considered with reference to the three principal types of deformations: axial, curvature and racking (rectangular cross-sections), or ovaling (circular crosssections). Axial and curvature deformations develop when seismic waves propagate either parallel or obliquely to the longitudinal axis of the structure (Figure 1a). The general behaviour of a long structure subjected to a component of parallel wave deformation is similar to that of an elastic beam embedded in the soil. In simplified analyses, the structure is assumed to be flexible relative to the surrounding soil or rock, and to respond with the same deformation pattern as in the free-field elastic seismic waves. These simplified analyses are often employed for pipelines that have relatively small cross-sectional areas and for the preliminary analyses of tunnels. When the structure is stiff in the longitudinal direction relative to the surrounding soil, it will not be compliant with the soil or rock deformations. For this case, interaction effects need to be considered by employing either numerical methods or approximate solutions developed from wave propagation theory for beams on an elastic foundation (Wang, 1993).

Ovaling or racking deformations develop in an underground structure when the seismic waves propagate in a direction perpendicular to, or with a significant component perpendicular to, the longitudinal axis, resulting in distortion of the cross-section (see Figure 1b). For this case, and if the structure is relatively long, a plane-strain two-dimensional analysis may be employed.

In the past, earthquake analysis of underground structures focused on circular cavities in elastic continua and then advanced to consider lined cavities located within elastic half-spaces. These shapes were a reasonable approximation to typical tunnel cross-sections and could be analysed by analytical theory of elasticity and approximate elasticity methods. With the rapid advance of numerical methods in the last decade, satisfactory analysis procedures have been developed for rectangular structures. Prior to this, rectangular cross-sections were designed by assuming that they were subjected to the freefield soil or rock shear strains and by the application of standard structural frame analysis methods. Rectangular underground structures are suitable for cut-and-cover construction and are therefore often constructed close to the surface in relatively soft soils. In this situation, the assumption of compatibility with the free-field shear strains may in some cases lead to very conservative designs.

${ }^{1}$ John Wood Consulting, Lower Hutt (Fellow). 


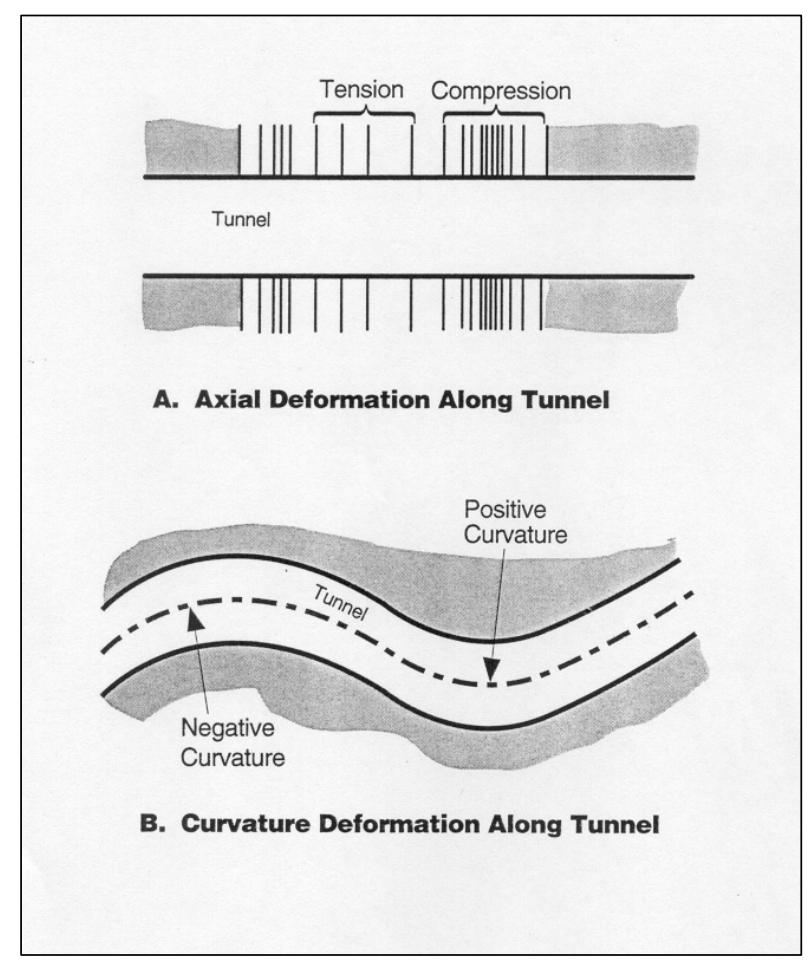

Figure 1a. Axial and curvature deformations. (Source Owen and Scholl, 1981)

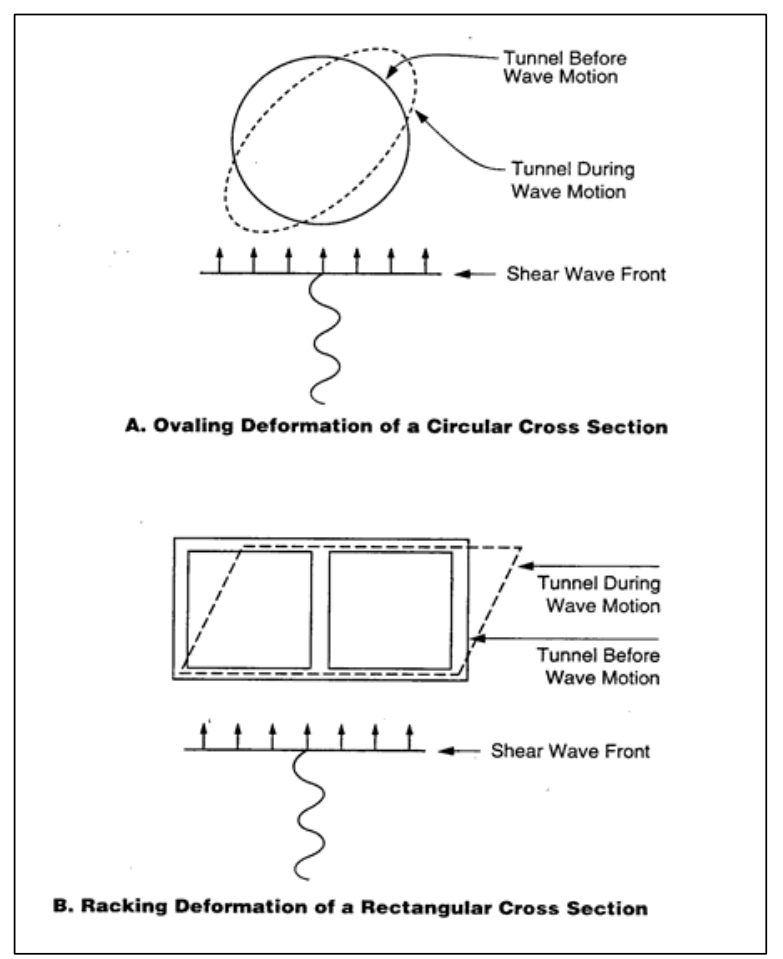

Figure 1b. Ovaling and racking deformations. (Source Yang, 1993)

shear waves in a layer of uniform thickness. These solutions provide sufficiently good approximations for the design of smaller underground structures, particularly where the site soil properties are not know in any great detail. They are also helpful in providing quick solutions for preliminary analysis work, and provide a useful verification method for more sophisticated numerical analysis.

In the present study, analytical solutions were evaluated for a uniform elastic shear layer of infinite horizontal extent overlying rock assumed to form a rigid lower boundary. Solutions were evaluated for the following depth profiles of the elastic shear modulus, $G$.

(a) Uniform.

(b) Parabolic with the surface value $\mathrm{G}_{\mathrm{t}}=0$.

(c) Linear variations with $\mathrm{G}$ increasing with depth. $\mathrm{G}$ defined by $\mathrm{G}(\mathrm{y})=\mathrm{G}_{\mathrm{b}}(1-\mathrm{q} \mathrm{y} / \mathrm{H})$, where $G_{b}$ is the shear modulus at the base of the layer, $y$ is the height above the base, $\mathrm{H}$ is the thickness of the layer and $\mathrm{q}$ is a parameter varying between 0 and 1 .

Plots of $G$ versus depth for the layers investigated are shown in Figure 2. Layers included uniform, parabolic, and linear variations with $\mathrm{q}=0.75,0.95,0.9$ and 0.95 . Analytical solutions by Wood (1973) were used to evaluate first horizontal mode displacement and shear strain responses for $H=50 \mathrm{~m}, G_{\text {ave }}=100 \mathrm{MPa}$, and uniform soil density $\rho=2.0 \mathrm{t} / \mathrm{m}^{2}$. First mode displacement and shear strain responses calculated for a one-g static 
base acceleration are shown in Figures 3 and 4. First mode periods of vibration for the analysed layers are given in Table 1. The response to a dynamic base acceleration input is obtained by scaling the one-g static responses by $\mathrm{Sa}\left(\mathrm{T}_{1}\right) / \mathrm{g}$ where $\mathrm{Sa}\left(\mathrm{T}_{1}\right)$ is the spectral acceleration of the input acceleration response spectrum at $\mathrm{T}_{1}$, the first horizontal mode period of the layer.

Table 1. First mode periods

\begin{tabular}{|l|l|}
\hline $\begin{array}{l}\text { Layer } \\
\text { Description }\end{array}$ & $\begin{array}{c}\text { Period, } \\
\mathbf{T}_{\mathbf{1}} \mathbf{s e c}\end{array}$ \\
\hline Uniform & 0.894 \\
\hline Parabolic & 0.811 \\
\hline Linear, q = 1.0 & 0.826 \\
\hline Linear, q =0.95 & 0.819 \\
\hline Linear, q =0.90 & 0.818 \\
\hline Linear, q =0.75 & 0.826 \\
\hline
\end{tabular}

\subsection{Structure Stiffness and Flexibility}

Most underground structures of rectangular shape are designed to act as rigid-jointed box structures. The simplest example of this type of structure is the singlebarrel box shown in Figure 5. To assess the racking stiffness or flexibility, the structure is loaded with a horizontal load $\mathrm{P}$ at the roof level to produce a racking or shear deformation of $\Delta$. The structure is assumed to be of sufficient extent normal to the plane of the section for plane-strain conditions to exist. Simple closed-form solutions for the racking stiffness and flexibility of this single-barrel structure have been published previously (Shepherd \& Wood, 1966). The elastic flexibility can be written as:

$$
f_{s t}=\frac{\Delta}{P}=\frac{H^{2}}{24 K_{w}}\left[1-\frac{2+3 r+3 j r}{2+2 r(2+2 j+3 j r)}\right]
$$

Where:

$$
K_{w}=\frac{E I_{w}}{H} \quad K_{r}=\frac{E I_{r}}{L} \quad r=\frac{K_{r}}{K_{w}}
$$

$E$ is Young's modulus for the structure material and $I_{w}$ and $I_{r}$ are the moments of inertia per unit length of the wall and roof respectively. $H, L$ and $j$ are defined in Figure 5.

There are no simple closed-form solutions available for multi-barrel structures, but reducing the multi-barrel structure to an equivalent single-barrel structure can provide a good approximation (within 6\%) for the stiffness or flexibility. Each wall element of the equivalent singlebarrel structure has one-half of the sum of the flexural stiffness of all the wall elements in the multi-barrel structure, and the roof and floor elements of the equivalent structure have the sum of the corresponding roof or floor elements in the multi-barrel structure.

Under high racking deformations, yield in the members may occur leading to plastic hinge formation in the walls, roof or floor members. Progressive development of the hinges can be investigated by a pushover analysis using nonlinear frame analysis software.

\subsection{Soil-Structure Interaction}

Because of both soil-structure interaction and dynamic inertial effects, the soil shear strains in the vicinity of the structure are generally significantly different to the freefield shear strain at the corresponding depth in the soil layer. Often the mass change at the cavity created by the structure is small in relation to the total mass in the layer acting in unison with the structure during dynamic loading, and previous research has indicated that dynamic inertial effects are sufficiently small to be neglected.

In contrast to the influence of soil inertial effects, soilstructure interaction effects may produce significant changes in the shear strains near the structure. If a cavity in the soil is unlined, then the shear strains in the soil near the cavity would clearly be greater than the free-field shear strain. If a stiff structure is inserted in the soil cavity, then the shear strains may be less than the free-field. Conversely, with a very flexible structure, the shear strains may be greater than in the free-field.

In assessing soil-structure interaction effects on underground structures it is usual to define shear strain deformation and flexibility ratios. The shear strain deformation ratio, $\mathrm{R}$, is defined by:

$$
R=\frac{\begin{array}{c}
\text { Shear deformation of structure } \\
\text { embedded in soil (including interaction) }
\end{array}}{\begin{array}{c}
\text { Free-field shear deformation } \\
\text { over height of structure }
\end{array}}=\frac{\Delta_{s t i}}{\Delta_{f f}}
$$

The flexibility ratio, $F_{r}$ is defined by:

$$
F_{R}=\frac{\begin{array}{c}
\text { Shear flexibility of free standing } \\
\text { structure without soil interaction }
\end{array}}{\begin{array}{c}
\text { Shear flexibility of soil block of same } \\
\text { overall dimensions as structure }
\end{array}}=\frac{f_{s t}}{f_{s}}
$$

Soil shear stiffness is defined by:

$$
K_{s}=G=\frac{\tau}{\gamma}
$$

Where: $G=$ soil shear modulus in the soil at the level under consideration, $\tau=$ soil shear stress and $\gamma=$ soil shear strain.

From the soil shear stiffness definition it follows that the shear flexibility of a block of soil of height $\mathrm{H}$ and length $\mathrm{L}$ is given by:

$$
f_{s}=\frac{H}{L G}
$$

The flexibility ratio $F_{r}$ can be readily computed from the soil shear modulus $G$ and the structure flexibility coefficient $f_{s t}$. Methods for calculating the shear deformation ratio $R$ from the flexibility ratio have been investigated in several previous research projects (Wang, 1993; Penzien, 2000; Nishioka and Unjoh, 2003) and also in the present study. The structure shear deformation (including soil-structure interaction) $\Delta_{s t i}$ can be readily 
calculated from the shear deformation ratio $R$ and estimates of the peak free-field shear deformation $\Delta_{f f}$ during the design earthquake event. The structure shear deformation can be used to calculate the earthquakeinduced forces in the members of the structure using analytical or numerical methods. For example, the moment at the base joints of a single-barrel box are given by Wood, 2004 as:

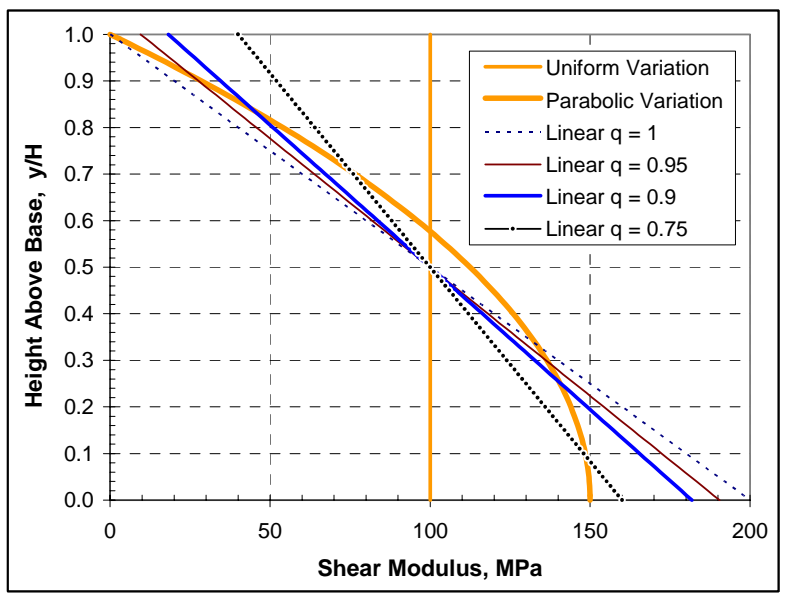

Figure 2. Variation of layer shear modulus, $\mathbf{G}$.

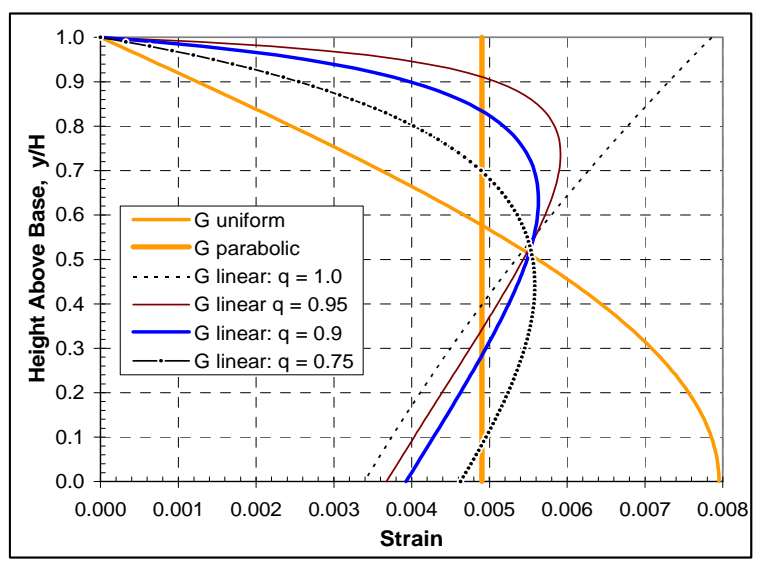

Figure 4. First shear mode shear strain response.

$$
M_{f}=\frac{6 \Delta K_{w}}{H}\left[\frac{j(3+q)}{j-(2 j+q)(2+q)}\right]
$$

Where

$$
q=\frac{K_{w}}{K_{r}}
$$

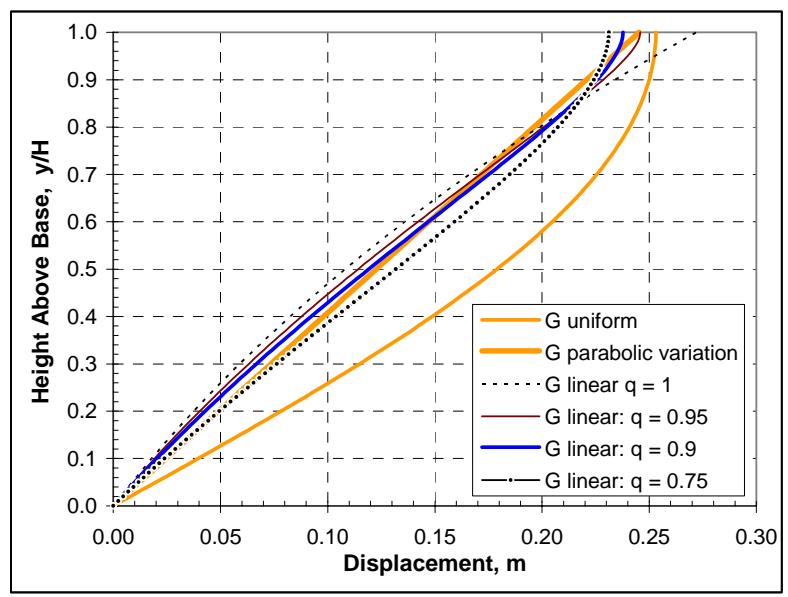

Figure 3. First shear mode displacement response.

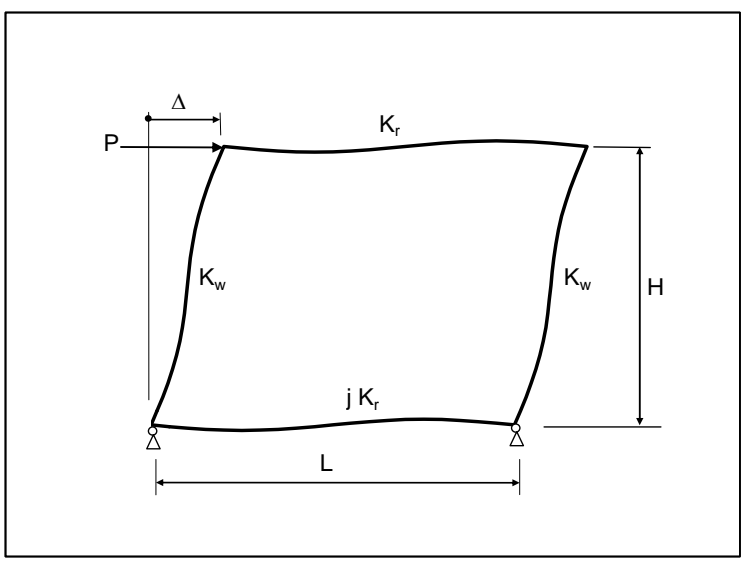

Figure 5. Single-barrel box frame.

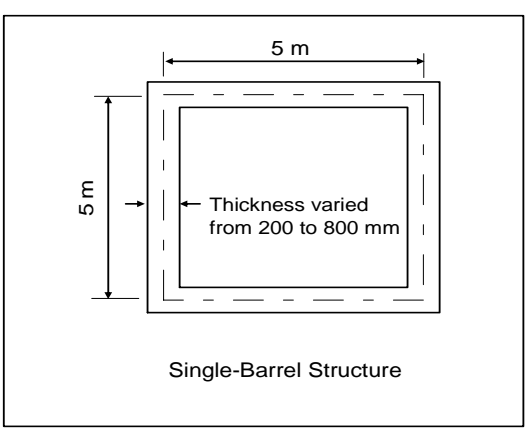

Figure 6a. Single-barrel box model

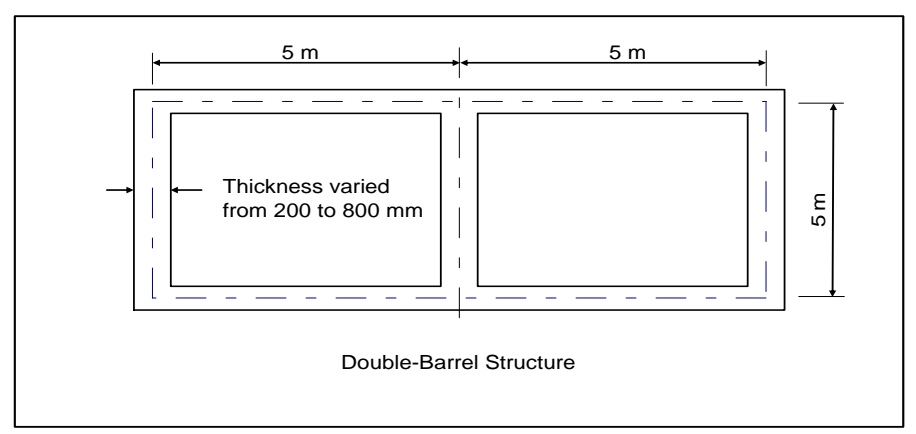

Figure 6b. Double-barrel box model. 
In the present study, $R$ versus $F_{r}$ relationships were evaluated for box structures by simplifying a dynamic finite element analysis procedure originally used by Wang (1993). The dynamic analysis was simplified by undertaking a modal analysis and investigating the strain field in the first mode of the soil layer. This simplification enabled a wide range of the important parameters to be investigated. By using a refined mesh, it was also possible to reliably calculate the forces in the members of the structure. The rigid-frame single-barrel and twin-barrel box structures shown in Figure $6 \mathrm{a}$ and $6 \mathrm{~b}$ were analysed using a range of layer depth and shear modulus profiles. Plane-strain conditions, and linearly-elastic material properties for soil and structure were assumed.

\section{RESULTS OF ANALYSES}

$R$ versus $F_{r}$ curves for the single and twin-barrel structures analysed in the present study using a soil Poisson's Ratio

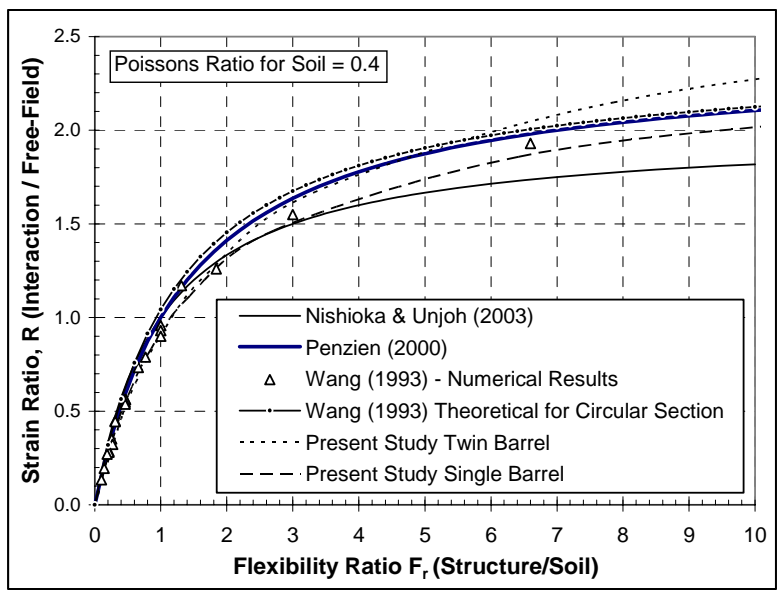

Figure 7. Interaction curve comparison.

$R$ versus $F_{r}$ curves for the single-barrel structure in a uniform $50 \mathrm{~m}$ thick layer are shown in Figure 8 for a range of different cover depths. There is little variation between the curves for cover depths between 5 and $20 \mathrm{~m}$. Surfacelayer effects cause moderate changes in the interaction for shallow covers at high $\mathrm{F}_{\mathrm{r}}$ ratios, but once the structure is covered by more than its height of soil, the interaction does not change significantly with increasing depth of the structure within the layer.

The effects of the depth of the layer, strain profile, Poisson Ratio and the box shape on the interaction curves are presented by Wood (2004) in a more detailed report on the present study. Provided the depth of cover is greater than the height of the structure, it was found that the variation in the shear modulus or strain field has little influence on the interaction curves.

The bending moments and shear forces at the bottom of the side-wall members for the single and twin- barrel box structures with a $5 \mathrm{~m}$ depth of cover are shown in Figures 9 and 10. Both the plotted interaction bending moments and shear forces have been normalised by dividing the computed values by the corresponding values for the of 0.4 , depth of cover of $5 \mathrm{~m}$ and a $50 \mathrm{~m}$ deep soil layer with a shear modulus increasing parabolicaly from zero at the surface are compared in Figure 7 with the results of Wang (1993), Penzien (2000), and Nishioka and Unjoh (2003), for similar assumptions. There is good general agreement between the $R$ versus $F_{r}$ curves produced by the various methods, particularly at $F_{r}$ ratios less than 2.0.

The results in Figure 7 show that when the flexibility ratio approaches zero, representing a perfectly-rigid structure, the $R$ value also reduces to zero. At $F_{r}=1$, the structure has the same stiffness as the soil, and the structure has a similar racking distortion to the ground in the free-field, resulting in an $R$ value of approximately 1.0. When the flexibility ratio is greater than 1.0 , the structure is flexible with respect to the ground, and the racking distortions become magnified with respect to the free-field shear distortion.

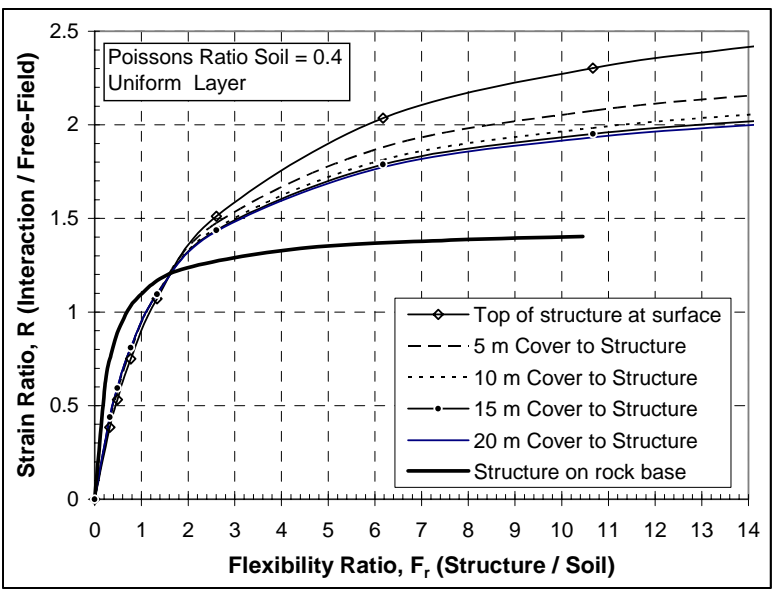

Figure 8. Interaction for single barrel at various depths.

structures without surrounding soil. Similar variations with $F_{r}$ were obtained for the moments and shears at the tops of the walls (Wood, 2004).

From Figures 9 and 10 it is apparent that the interaction effects significantly modify the bending moments and shear forces in the box members for large $\mathrm{F}_{\mathrm{r}}$ ratios.

\section{BOX CULVERT ANALYSIS EXAMPLE}

Table 2 summarises calculations based on the above analysis procedure for a large single-barrel box culvert with outside dimensions $4 \times 4 \mathrm{~m}$ and uniform wall thickness of $400 \mathrm{~mm}$. The structure was assumed to be covered by $5 \mathrm{~m}$ of soil in a $50 \mathrm{~m}$ deep soil layer with a Poisson's ratio of 0.4 and shear modulus varying parabolicaly from zero at the surface to $200 \mathrm{MPa}$ at a rigid base. It was assumed that the cracked stiffness of the walls was $50 \%$ of the elastic stiffness. A ground-surface design acceleration of $0.4 \mathrm{~g}$ was adopted.

For the assumed soil profile, the structure has a flexibility ratio $F_{r}$ of 2.27 , indicating that it is more flexible than the 


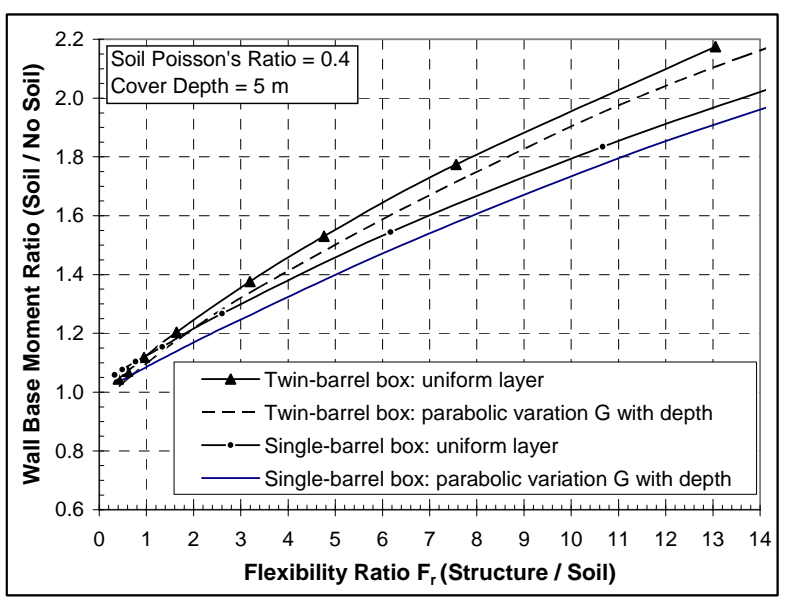

Figure 9. Bending moments at base of side wall.

replaced soil, with the induced strain greater than the freefield strain by a moderate margin (strain ratio $R=1.4$ ). The maximum earthquake-induced moment at the base of the walls was $133 \mathrm{kN} \mathrm{m} / \mathrm{m}$ which is greater than the cracking moment of about $100 \mathrm{kN} \mathrm{m} / \mathrm{m}$, and of similar order to gravity and water pressure induced moments (Wood, 2004).

A refined version of the above analysis procedure is necessary when the nonlinear response of the structure becomes significant. In this case, it is necessary to carry out an inelastic pushover analysis of the structure (without soil interaction) to define the structure force/displacement relationship. The analysis is then advanced by estimating a ductility factor, calculating the equivalent flexibility factor, and undertaking a standard interaction analysis to estimate the total shear deformation of the structure. From this deformation and the yield displacement, an improved ductility factor can be calculated and the process repeated until convergence (Wood, 2004).

\section{CONCLUSION}

Large earthquake-induced forces in the culvert structure of the above example indicate that earthquake racking effects need to be considered in the design of rectangular underground structures. The analysis method first described by Yang (1993) and advanced in the present study provides a suitable design approach for small structures and preliminary design for large structures.

\section{ACKNOWLEDGEMENT}

Financial support from the Earthquake Commission Research Foundation to undertake this project is gratefully acknowledged.

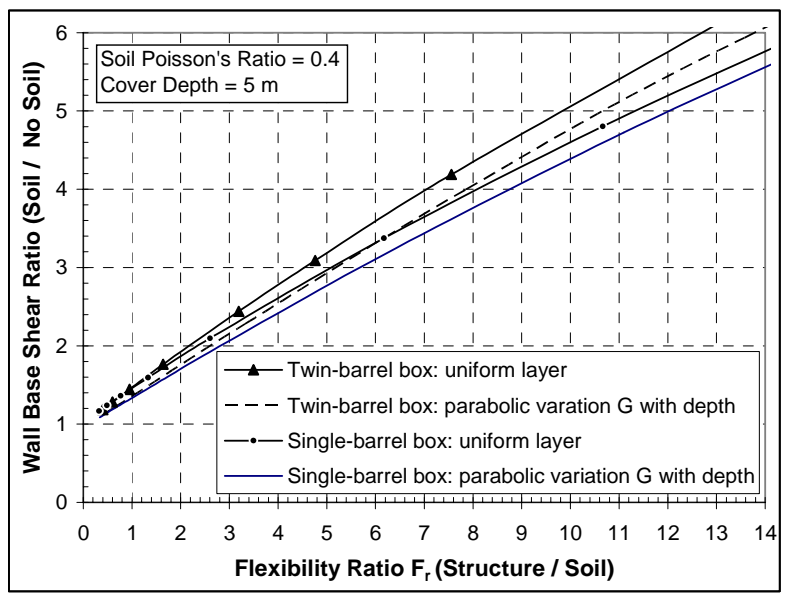

Figure 10. Shear force at base of side wall.

\section{REFERENCES}

Nishioka, T. \& Unjoh, S. (2003). "A simplified evaluation method for the seismic performance of underground common utility boxes". Proceedings 2003 Pacific Conference on Earthquake Engineering, NZSEE, Auckland.

Owen, G.N. \& Scholl, R.E. (1981). "Earthquake engineering of large underground structures". Report prepared for the Federal Highway Administration, FHWAIRD-801195.

Penzien, J. (2000). "Seismically induced racking of tunnel linings". Earthquake Engineering and Structural Dynamics, Vol 29, 683-691.

Shepherd, R. \& Wood, J.H. (1966). "Normal mode properties of multi-storey frameworks". Journal of Sound and Vibration, Vol. 3, No. 3, 300-314.

Wang, J. (1993). "Seismic design of tunnels". Monograph 7, Parsons Brinckerhoff Quade \& Douglas Inc, New York, June 1993.

Wood, J.H. (2004). "Earthquake design procedures for rectangular underground structures". Project Report to Earthquake Commission, EQC Project No. 01/470, Rev B July 2004.

Wood, J.H. (1973). "Earthquake-induced soil pressures on structures". EERL 73-05, Earthquake Engineering Research Laboratory, California Institute of Technology. 